\title{
IMPACT OF LAND USE CHANGE TO THE SOIL EROSION ESTIMATION FOR CULTURAL LANDSCAPES: CASE STUDY OF PAPHOS DISRICT IN CYPRUS
}

\author{
B. Cuca ${ }^{\mathrm{a}}$, A. Agapiou ${ }^{\mathrm{b}}$ \\ ${ }^{a}$ Dept. of Architecture, Built Environment and Construction Engineering, \\ Politecnico di Milano, Via Ponzio 31, 20133 Milan, Italy - branka.cuca@polimi.it \\ ${ }^{\mathrm{b}}$ Dept. of Civil Engineering and Geomatics, Cyprus University of Technology, \\ Saripolou 2-8,3 3036 Limassol, Cyprus - athos.agapiou@cut.ac.cy
}

Commission VI, WG VI/4

KEY WORDS: Soil erosion, Land use change, RUSLE/USLE, GIS, Cultural landscapes, Earth Observation, satellite remote sensing

\begin{abstract}
:
In 2006 UNESCO report has identified soil loss as one of the main threats of climate change with possible impact to natural and cultural heritage. The study illustrated in this paper shows the results from geomatic perspective, applying an interdisciplinary approach undertaken in order to identify major natural hazards affecting cultural landscapes and archaeological heritage in rural areas in Cyprus. In particular, Earth Observation (EO) and ground-based methods were identified and applied for mapping, monitoring and estimation of the possible soil loss caused by soil erosion. Special attention was given to the land use/land cover factor (C) and its impact on the overall estimation of the soil-loss. Cover factor represents the effect of soil-disturbing activities, plants, crop sequence and productivity level, soil cover and subsurface bio-mass on soil erosion. Urban areas have a definite role in retarding the recharge process, leading to increased runoff and soil loss in the broader area. On the other hand, natural vegetation plays a predominant role in reducing water erosion. The land use change was estimated based on the difference of the NDVI value between Landsat 5 TM and Sentinel-2 data for the period between 1980s' until today. Cover factor was then estimated for both periods and significant land use changes were further examined in areas of significant cultural and natural landscape value. The results were then compared in order to study the impact of land use change on the soil erosion and hence on the soil loss rate in the selected areas.
\end{abstract}

\section{INTRODUCTION}

Soil erosion, has a negative impact on ecosystem services, crop production, drinking water, carbon stocks and it can seriously threaten and damage landscapes features, agricultural landscapes and natural resources in general. In addition, soil erosion is considered one of the major climate change threats affecting cultural heritage and landscapes (UNESCO report ed. Colette, A., 2006). In Panagos et al. (2015), an annually total soil loss of $970 \mathrm{Mt}$ has been estimated for the European Union, highlighting that the highest rates have been observed in Mediterranean countries. The study has shown that eight Mediterranean countries of European Union (including Cyprus) account the $67 \%$ of the total soil loss of all $28 \mathrm{EU}$ Member States. A high soil loss rate in these Mediterranean countries is also probably caused by the highest rainfall erosivity of Europe. The current work, illustrates the local dynamics of soil erosion and the estimation of possible soil loss, affecting the Paphos District of Cyprus. The focus is given on the impact of land use change to soil erosion, especially with regards to landscapes with cultural interest and archaeological heritage sites.

\section{CASE STUDY: CULTURAL LANDSCAPES OF PAPHOS, CYPRUS}

The paper proposes the methodology for estimation of land cover impact in the soil erosion, using satellite remote sensing imagery for the district of Paphos in Cyprus. The city of Paphos, at $34^{\circ} 46^{\prime} \mathrm{N} 32^{\circ} 25^{\prime} \mathrm{E}$ coordinates, has a subtropicalMediterranean climate, with the mildest temperatures on the island. The landscape in the Paphos area varies from the coastal plain, the hilly area extending from the coastal plain up to the igneous rocks of Paphos forest and finally the mountainous region of Troodos.

Paphos has a long history and combines both World Heritage Monuments as well as other isolated monuments and archaeological sites. The ancient town of Palaipaphos, one of the World Heritage Monument, is located within the limits of the modern village of Kouklia, situated close to the mouth of Diarizos river, 16 kilometres east of the modern town of Paphos. The site of Palaipaphos and its surrounding area are linked to an ancient cult associated with the "Great Goddess", the goddess of fertility, who was worshiped in Cyprus since the Neolithic period. The other World Heritage site, Nea Pafos is situated on a small promontory on the southwest coast of the island. According to written sources, the town was founded at the end of the 4th century by Nicocles, the last king of Palaipafos. In the beginning of the 3rd century B.C. when Cyprus became part of the Ptolemaic kingdom, which had its capital in Alexandria, Nea Pafos became the center of Ptolemaic administration on the island. Until the end of the 2nd century B.C. (DoA, 2017). 


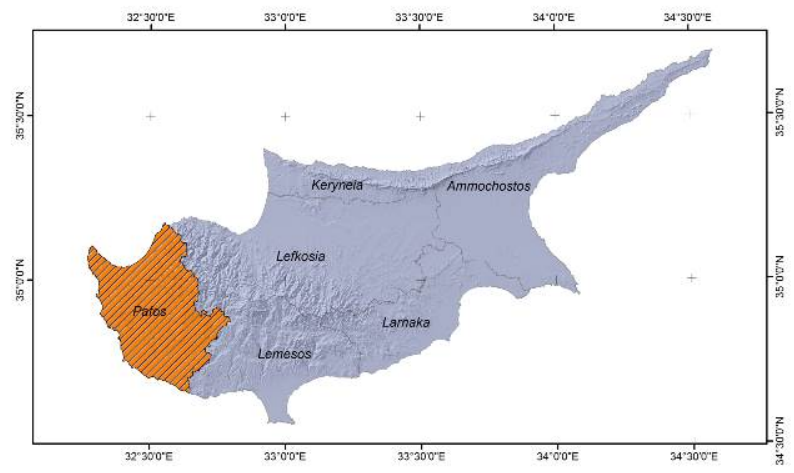

Figure 1. District of Paphos, situated in the western part of the Cyprus island

\section{USLE/RUSLE METHODOLOGY APPLIED USING SATELLITE REMOTE SENSING DATASETS}

This paper builds up on the results of a previous work (Alexakis et al. 2013; Cuca et al. 2017), in which the authors have illustrated some preliminary results of soil loss estimation for Paphos district over the period of last 10 years using a widely used method for soil-loss evaluation - a mathematical model called RUSLE/USLE (Revised USLE - Universal Soil Loss Equation).

Since it is based on the use of EO geomatics data, such method offers the possibility for the same procedure to be replicated and applied on different areas or on the same area for different time periods. Furthermore, it is highly compatible with elaboration in Geographic Information Systems (GIS). Also RUSLE method is able to estimate erosion rates within the spatial limits of a watershed basin and to present the spatial heterogeneity of soil erosion phenomenon.

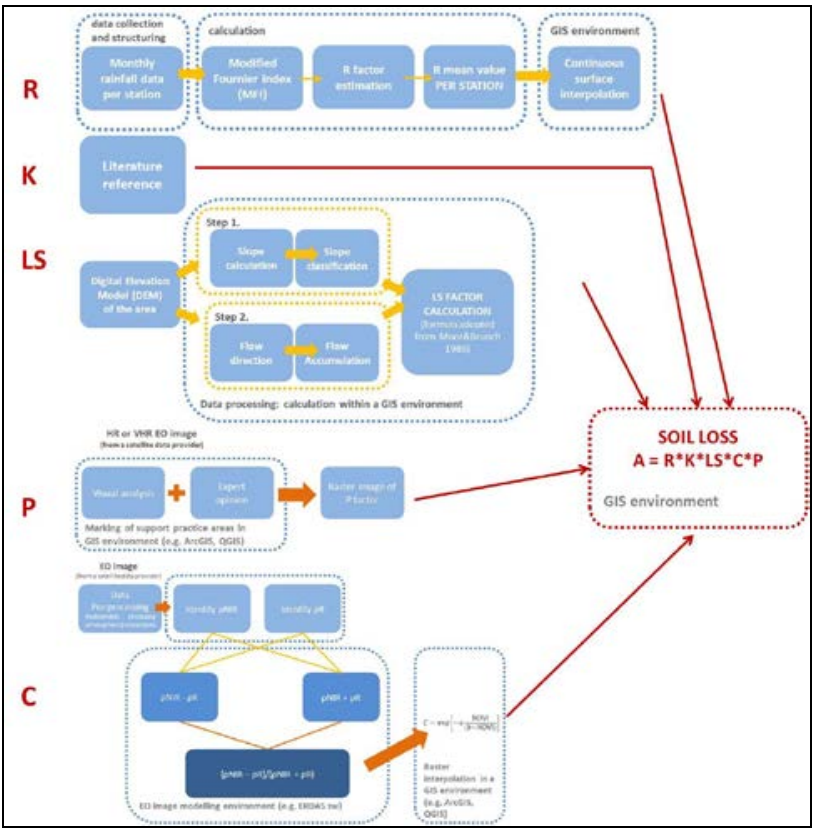

Figure 2. Overall Processing chain for Soil Loss calculation using RUSLE/USLE equation

The RUSLE model consists of five different factors: $\mathrm{A}=$ $\mathrm{R} * \mathrm{~K} * \mathrm{LS} * \mathrm{C} * \mathrm{P}$ here (A) stands for Annual average soil loss ( $\mathrm{t}$ ha-1 yr-1), R stands for rainfall erosivity (MJ mm ha-1 h-1 yr1), $\mathrm{K}$ for soil erodibility ( $\mathrm{t}$ ha h ha-1 MJ-1 mm-1), LS for a composite topographic factor i.e. factor of slope length (L) and slope steepness (S) (dimensionless), $\mathrm{C}$ for the cover management (dimensionless), and $\mathrm{P}$ stands for support practice i.e. manmade actions to prevent and mitigate effects of soil erosion (dimensionless). The overall processing chain applied is illustrated in Figure 2.

The final results have given an illustration of the soil loss rate effecting Paphos district and in particular the Nea Paphos archaeological site and the surrounding area (Figure 3).
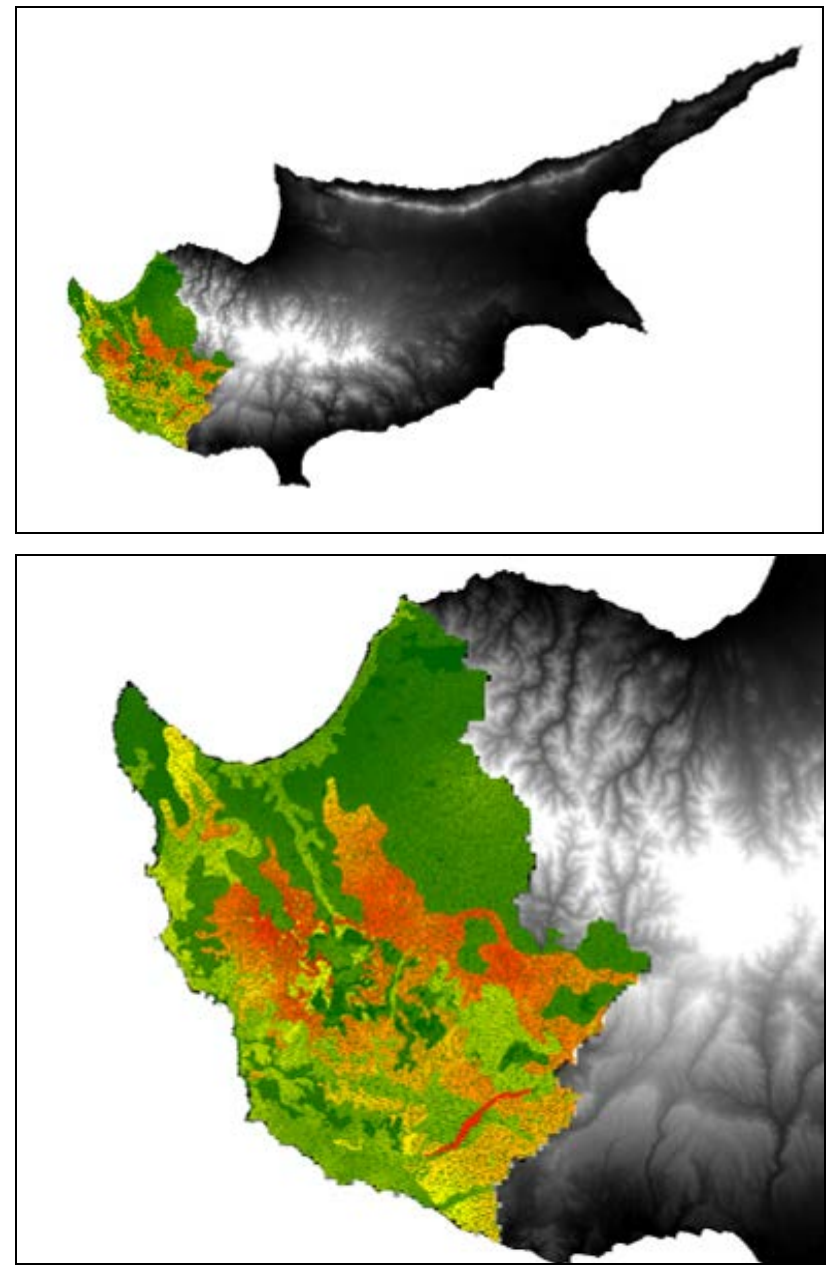

Figure 3. Map of Soil Loss estimated using RUSLE method for Paphos District over Cyprus DEM (above) and a detail (below)

In the study presented here authors aim to demonstrate the calculation methods and assumptions used to obtain the values of all RUSLE factors with focus on Land cover factor (C) and to which extent the changes in land use (hence its cover) could affect the amount of soil eroded, possibly even in proximity of heritage sites and landscape of environmental, cultural and touristic value.

\subsection{Datasets}

The main data used to observe the changes in landscape of Paphos district were freely available satellite imagery Landsat (accessed and downloaded from the geo-portal of the Geographical Survey of United States - USGS) and Sentinel-2 images (accessed and downloaded from the scientific hub portal of European Space Agency). Cloud free, calibrated satellite images used regard the years 1987 and 2016, covering the same season, minimizing in this way seasonal variations. 
The images were used as means to observe possible changed in urban fabric and to investigate variations in surrounding landscape for the period between the 1980s (years of construction sector "boom" recorded in Cyprus) and current situation. Images used are described in details in Table 1:

Table 1 Satellite imagery used in the study

\begin{tabular}{|c|c|c|c|}
\hline $\begin{array}{l}\text { Year } \\
\text { (date- } \\
\text { month) }\end{array}$ & $\begin{array}{l}\text { Satellite } \\
\text { (Sensor) }\end{array}$ & $\begin{array}{l}\text { Spatial } \\
\text { resolution (m) } \\
\text { (VIS and VNIR) }\end{array}$ & $\begin{array}{l}\text { Spectral } \\
\text { Resolution } \\
\text { (nm) } \\
\text { (only VIS- } \\
\text { VNIR listed) }\end{array}$ \\
\hline $\begin{array}{c}1987 \\
\text { (22-April) }\end{array}$ & $\begin{array}{c}\text { Landsat5 } \\
\text { (Thematic } \\
\text { Mapper - } \\
\text { TM) }\end{array}$ & 30 & $450-900$ \\
\hline $\begin{array}{c}2016 \\
\text { (29-April) }\end{array}$ & Sentinel-2 & 10 & $490-900$ \\
\hline
\end{tabular}

Figure 4 shows the city of Paphos in the year 2016 observed in a multi-spectral image through different band combinations.
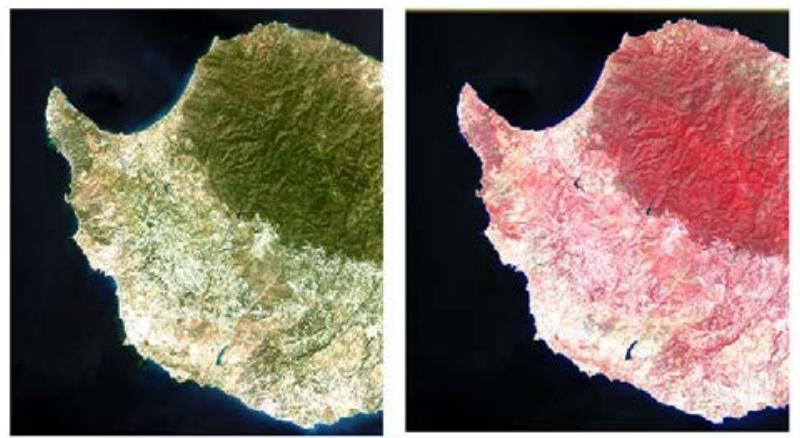

Figure 4. The city of Paphos in the year 2016: (left) Red Green - Blue (RGB) true colour composite i.e. the band combination that corresponds to the human vision; and (right) in NIR - green - blue pseudo colour composite that enhances the presence of vegetation (in red colour).

\section{METHODOLOGY FOR EVALUATION OF LAND USE CHANGE IMPACT OF SOIL EROSION}

In order to evaluate the impact of land use change to the soil erosion estimation, authors here propose to proceed in four main steps (Figure 5):

1) Step 1: Calculation of the Normalized Difference Vegetation Index (NDVI);

2) Step 2: Estimation of the Land use Land Cover (LULC) changes as calculated by the difference and thresholding of the NDVI images;

3) Step 3: Calculation of the RUSLE C factor (linked with NDVI values);

4) Step 4: Temporal difference of the $\mathrm{C}$ factor, highlighting significant changes in land cover with potential impact on the soil erosion.

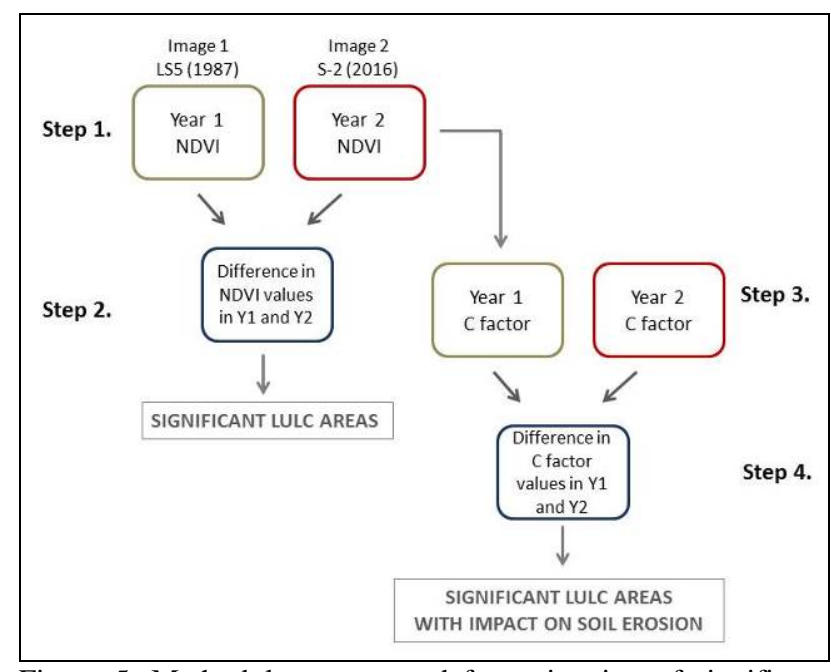

Figure 5. Methodology proposed for estimation of significant land change areas with possible impact on soil erosion

\section{RESULTS ILLUSTRATION}

In case of Paphos District, NDVI was calculated for both 1987 and 2016 image. Then the difference of the NDVI index for the period of circa 30 years in the area was calculated (Figure 6).
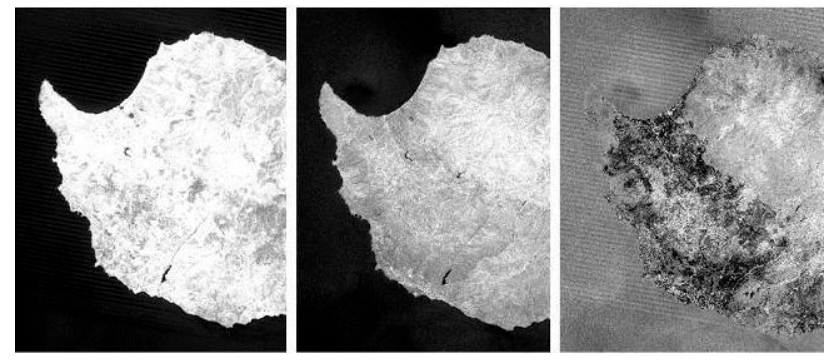

Figure 6. NDVI in Paphos District: in 1987 (left), in 2016 (middle). The difference between 1987 and 2016 (right).
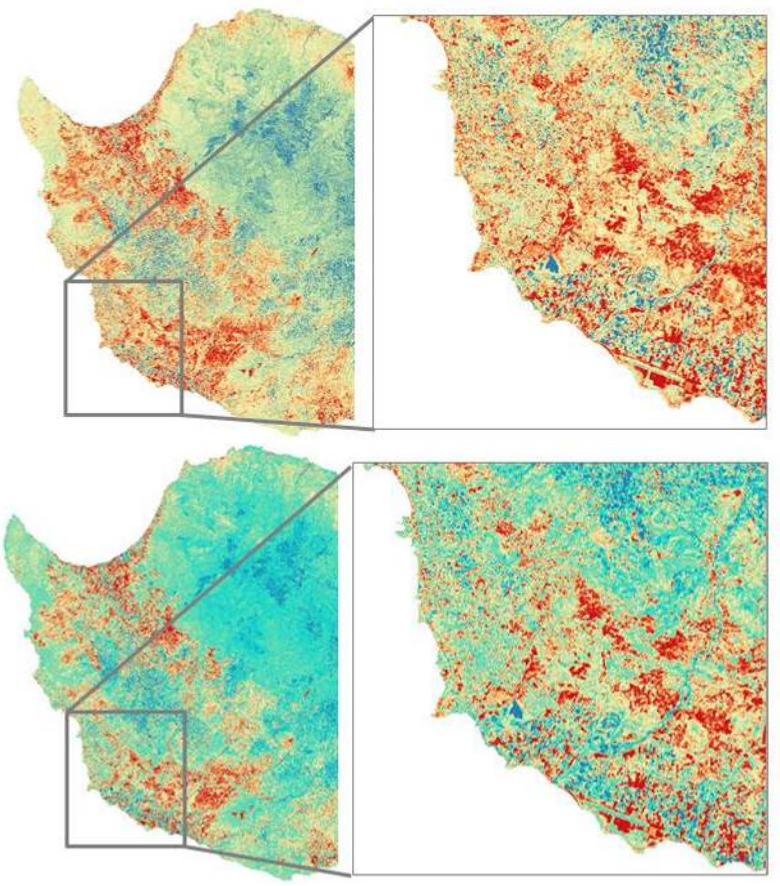

Figure 2 Differences in NDVI values in false colours 
Based on this result, it was possible to map some significant land use changes taken place in these last 30 years. It should be stressed that such land use changes could be either linked to natural or anthropogenic impacts. The NDVI difference image was then classified using false colour gradients for different thresholds, considering both positive and negative changes i.e. increase and decrease of areas occupied by the live vegetation (Figure 5).

In particular a threshold of 0.2 which is considered to be an approximate value indicating healthy vegetation, was applied. Threshold filter was able to provide some "hot-spots" regions in the area under investigation. Such regions (Step 2) were considered to be significant Land use Land Cover (LULC) areas (Figure 6).

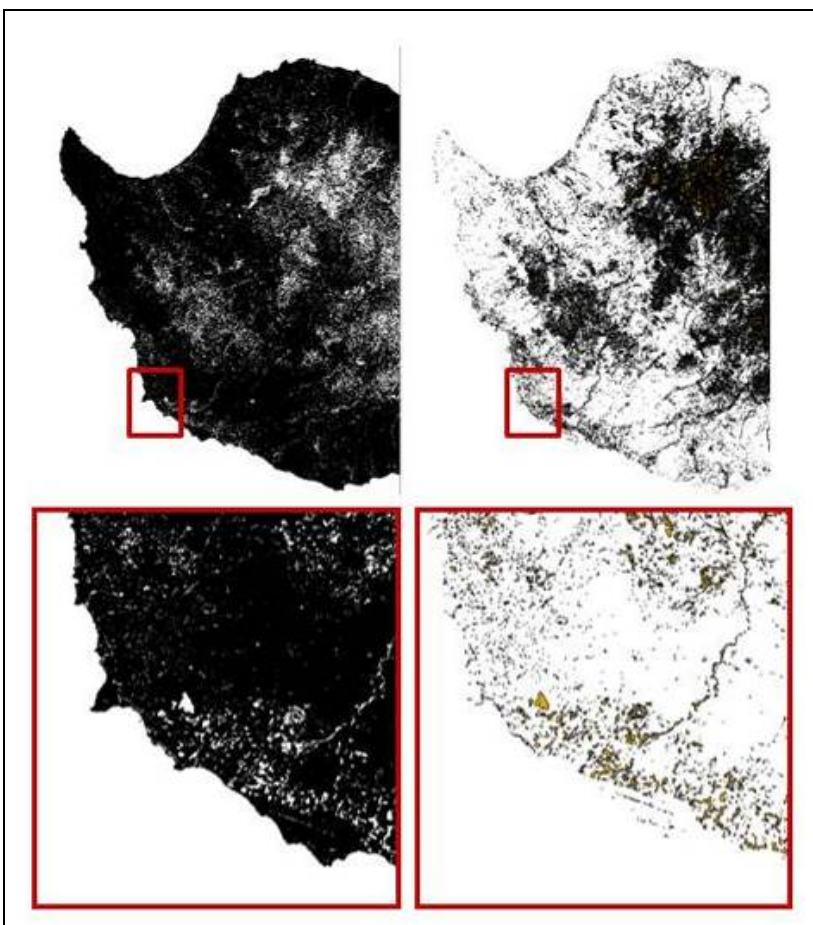

Figure 3. Normalization of significant areas for threshold 0.2 : all changes below this threshold were given the value of 0 , all values above 0.2 were given the value of 1 . Above left raster image and above right vector values obtained through vectorization procedure; respective details below.

\section{DISCUSSION}

\subsection{Comparison between differences in NDVI values and in $\mathrm{C}$ factor values}

In order to explore the impact of the land use change on soil erosion, the C factor of RUSLE method was re-calculated for both 1987 and 2016, using the expression (1):

$\mathbf{C}=\exp \left[-\mathbf{a} \frac{\text { NDVI }}{(\mathbf{b}-\mathrm{NDVI})}\right]$

where $a=1$ and $\mathrm{b}=1$.

The results were than compared and the difference in $\mathrm{C}$ factors was determined. The significant LULC areas were then further observed on these results, comparing them also to the differences between in NDVI values.

The final results were then observed in a red range false colour image: the areas that have undergone significant changes are highlighted in red and dark red colour. Despite the low resolution of the freely distributed satellite images, important aspects regarding soul erosion can be seen for cultural hetiage sites and landscapes. As shown for instance in Figure 7, "Nea Paphos" archaeological site is vulnerable to soil erosion hazard. Though the site has been characterized as World Heritage monument, and therefore protected from anthropogenic hazards such as urban expansion (Agapiou et al., 2015, Agapiou et al, 2016), natural threats such as soil erosion can have a significant impact on the site and its surrounding ecosystem. It should be stressed that within the archaeological area, only some parts have been excavated and therefore some significant archaeological findings are expected to be found in the future by the archaeological community. These concealed remains however may be disturbed and even destroyed by the high rate of soil erosion in the area.

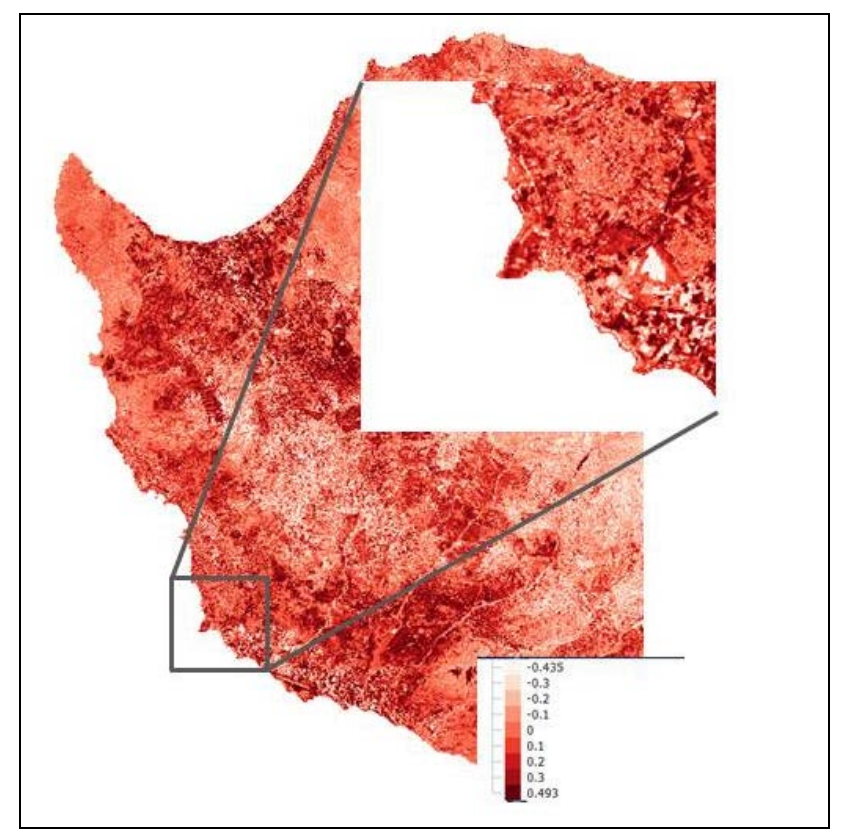

Figure 7. Difference in C-factor over nearly last 30years observed false colour: more significant changes possibly impacting the erosion of the soil in Paphos District are highlighted in red and dark red colour.

Further comparison of the results was then made by overlaying the significant LULC areas previously obtained in Step 2 for the area of World Heritage Site (WHS) of Nea Paphos. The results shown in Figure 8, illustrate how the significant changes observed in the surroundings the site, probably linked with the urban expansion of the city (indicated with circles), had a major impact to the $\mathrm{C}$ factor. It is also to be observed how these areas are situated in a very high proximity of the WHS (delimitation indicated with a dotted line). 


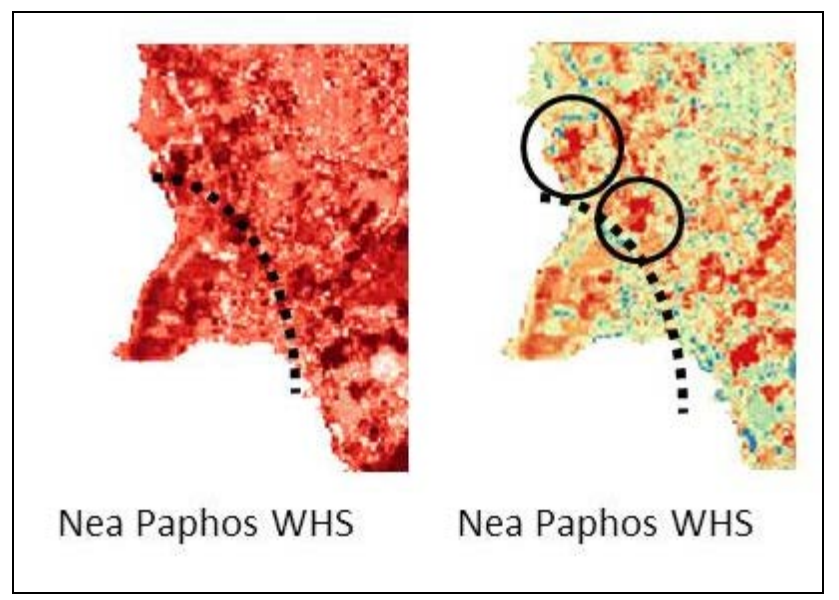

Figure 8 Difference in C-factor over nearly last 30years observed false colour, detail over Nea Paphos Cultural Heritage site (left) and with overlaid significant LULC areas obtained from NDVI calculations (right).

\section{CONCLUSIONS}

It has been acknowledged that the way in which the land is used varies over time this will inevitably effect the soil loss of any area. Looking closer into RUSLE Cover factor (C), it reflects the effect of cropping and management practices on erosion rates. In fact, $\mathrm{C}$ values are generally linked with various types of vegetation. However, in addition to vegetation, other land use types can also have low $\mathrm{C}$ values (such as parking lot, road, etc.) i.e. these areas could be considered as areas that haven't experienced any soil erosion over the period of time examined.

The work presented examines the impact of the land use change on the soil erosion, in the area of high cultural and natural value of Cyprus island. The paper illustrates a methodology for identifying significant Land Use Land Cover (LULC) areas and hence, through a comparison of $\mathrm{C}$ factor of a given area, also the significant LULC areas that could additionally have an impact on the erosion of soil and hence the negative impact on the surrounding landscape. This kind of evaluation is particularly interesting in regions like Paphos where a large portion of built cultural heritage is represented by archaeological sites, that often extend to entire landscape scale. The contribution of applied earth observation methodologies in this case highlight how analysis of environmental context can have interesting implications on risks evaluation to which important heritage sites like Nea Paphos are subject to. Further analysis, combined with in-situ confirmation and measurement, could provide additional information on the amplitude of the soil erosion phenomena that interests cultural landscapes of Paphos district, possibly contributing to targeted preventive measures for their better safeguarding in the future.

\section{ACKNOWLEDGEMENTS}

The results of these research activities have been partially funded within the project CLIMA (Cultural Landscape risk Identification, Management and Assessment), in the framework of Joint Programming Initiative for Cultural Heritage (JPI CH), agreement number KOINA/ПКП-HERITAGE PLUS/0314/07.

\section{REFERENCES}

Alexakis D. D., Agapiou A., Themistocleous K. , Lysandrou V., Sarris A., Hadjimitsis D. G., 2013. "Natural and human risk assessment of the archaeological sites of Paphos area (Cyprus) with the use of Remote Sensing and GIS”, Bulletin of the Geological Society of Greece, vol. XLVII 2013, Proceedings of the 13th International Congress, Chania.

Agapiou A, Alexakis DD, Lysandrou V, Sarris A, Cuca B, Themistocleous K, Hadjimitsis D.G., 2015. Impact of urban sprawl to archaeological research: the case study of Paphos area in Cyprus. J Cult Herit 16(5):671-680. doi:10.1016/j.culher.2014.12.006.

AgapiouA., Lysandrou V., Themistocleous K. \& Hadjimitsis D.G., 2016. "Risk assessment of cultural heritage sites clusters using satellite imagery and GIS: the case study of Paphos District, Cyprus”, Journal of the International Society for the Prevention and Mitigation of Natural Hazards, DOI 10.1007/s11069-016-2211-6.

Cuca B., Agapiou A., Tzouvaras M., Lysandrou V., Themistocleous K., Nisantzi Y., Evagorou E., Hadjimitsis D. G. 2017. Evaluating effects of Soil erosion by water on Cultural Heritage Sites: case study of Paphos district, Proc. of the Fifth International Conference on Remote Sensing and Geoinformation of the Environment 2017 (RSCy2017), 20-23 March, 2017, Cyprus.

Department of Antiquities, 2017, Nea Paphos (by Ministry of Transport, Communications and Works of the Republic of Cyprus), last accessed in April 2017 via http://www.mcw.gov.cy/mcw/da/da.nsf/DMLindex_en/DMLind ex_en

Panagos P., Borrelli P., Poesen J., Ballabio C., Lugato E., Meusburger K., Montanarella L., Alewell C., 2015. The new assessment of soil loss by water erosion in Europe, Environmental Science \& Policy 54, pp. 438-447, http://dx.doi.org/10.1016/j.envsci.2015.08.012. 